\title{
Ethylene thiourea: thyroid function in two groups of exposed workers
}

\author{
DONALDA M SMITH \\ From the Employment Medical Advisory Service, Worcester WR1 1UW
}

ABSTRACT Ethylene thiourea is manufactured at one factory in the United Kingdom and is mixed into masterbatch rubber at another. Clinical examinations and thyroid function tests were carried out over a period of three years on eight process workers and five mixers and on matched controls. The results show that the exposed mixers, but not exposed process workers, have significantly lower levels of total thyroxine $\left(T_{4}\right)$ than the controls. One mixer had an appreciably raised level of thyroid stimulating hormone (TSH).

Ethylene thiourea ( 2 mercaptoimidazoline) has been used as an accelerator in the rubber industry since 1948. It is also used as a chemical intermediate in the production of bactericides, pesticides and fungicides, dyestuffs, and photographic chemicals and was used at one time as a drug for treating thyrotoxicosis.

No hazard to health from this material was recorded until 1969 when liver tumours were reported in mice after the oral administration of 215 $\mathrm{mg} / \mathrm{kg} .{ }^{1}$ In 1972 the induction of thyroid carcinoma in rats and hypoplastic and simple goitre was reported after the oral administration of $350 \mathrm{ppm}^{2}$ The International Agency for Research in Cancer of the World Health Organisation ${ }^{3}$ has evaluated the carcinogenic risk of ethylene thiourea (ETU) to man and classified it as an antithyroid substance and as a suspect carcinogen, since this type of substance is believed to induce thyroid tumours through the suppression of thyroxin synthesis leading to hyperplasia of the thyroid gland.

In 1973 the Industrial Health Advisory Committee of the Department of Employment reported on ETU reviewing the evidence collected at that time (private communication). It concluded that unless there is clinical evidence of thyroid disease in exposed populations, it was unlikely that ETU would prove to be a thyroid carcinogen and suggested that the possibility of screening for thyroid stimulating hormone (TSH) on small, but highly exposed, industrial populations might be explored on a research basis. At the time this was thought

Received 7 March 1983

Accepted 26 September 1983 impractical in the United Kingdom since the small population at the one manufacturing plant was not thought to be highly exposed.

Two studies were carried out in the United States, however, by Gordon et $\mathrm{l}^{4}$ and by Braverman et al ${ }^{5}$ at Rohm \& Haas. They found that there was no significant effect on thyroid function in dithane workers; the tests used were total thyroxine $\left(T_{4}\right)$, triidothyroxine $\left(\mathrm{T}_{3}\right)$ resin uptake, and TSH.

In 1978 Lybarger carried out a study of the thyroid function of 54 workers at a plant which produces ETU in the United States. ${ }^{6}$ He tested $T_{4}$ and $T_{3}$ levels in 43 workers and 7 controls and found very slight differences. After this, NIOSH published a Current Intelligence Bulletin ${ }^{7}$ which was superseded by a Special Occupational Hazard Review. ${ }^{8}$ After this, it was decided that a survey should be carried out in the United Kingdom. The only company manufacturing ETU in this country was approached and agreed to an investigation of their process workers. The firm started mixing the ETU powder into masterbatch rubber on another site in 1977 and it was thought that the mixers might also be exposed to considerable quantities of ETU. These mixers were accordingly included in the survey in addition to the process workers.

The present study has been somewhat limited by the small number of workers and by the intermittent nature of the mixing work in 1980 and 1981 because of the economic recession. Since ETU is now being supplied only in the encapsulated form to rubber manufacturers, however, these process workers and mixers are the only ones in the United Kingdom exposed to an appreciable hazard of absorbing ETU. The British Rubber Manufacturer's Associa- 
tion Code of Practice ${ }^{9}$ states that there is no evidence of any carcinogenic or teratogenic hazard from the handling of finished rubber vulcanised with ETU, and NIOSH recommends complete conversion from the use of powdered ETU to encapsulated form. ${ }^{8}$

\section{Exposure}

\section{FACTORY 1: METHOD OF MANUFACTURE}

ETU is produced by reacting ethylene diamine with carbon disulphide $\left(\mathrm{CS}_{2}\right)$ in a closed reactor. This is followed by various processes to produce a dust suppressed powder that is bagged off under local exhaust ventilation. Some operations are very dusty, and the operatives exposed to high levels were wearing respirators; the greatest exposure was considered to occur in the bagging process. Until 1977 not all employees used respiratory protection or gloves, and the ventilation was not satisfactory at the weighing operation. This has now been rectified and exposures are thought to be lower than that measured in 1976 by the field consultant group of the Health and Safety Executive. Samples of background atmosphere were taken in various parts of the plant, and some personal samples were also taken. Levels up to $330 \mu \mathrm{g} / \mathrm{m}^{3}$ were found on one personal sampler; the background levels were in the range $10 \mu \mathrm{g} / \mathrm{m}^{3}-240 \mu \mathrm{g} / \mathrm{m}^{3}$. The operation is now noticeably less dusty but monitoring has not been repeated.

The jobs of the production workers are largely interchangeable so that differences in individual exposure are likely to be insignificant. The average length of exposure of these workers is 10 years with a range of five to 20 years.

\section{FACTORY 2}

At factory 2 the powder is mixed into ethylene propylene diene monomer (EPDM) rubber, and the mixture rolled into sheets. Originally the powder was supplied in paper sacks that were slit open and tipped into a Banbury mixer. This was a dusty process and in 1980 levels of $120-160 \mu \mathrm{g} / \mathrm{m}^{3}$ were recorded on personal samplers. From 23 February to 9 March 1981, the packaging was changed to a low melt plastic bag which was put into the mixer pierced but unopened. Loose powder was again used from 16 to 20 March 1981 . Since 4 May 1981 all the ETU has been in low melt plastic bags. A total of 46 tonnes of ETU was processed in 1981. In these operations the mixers are exposed to more ETU dust than the process workers. Four of the mixers experienced more exposure than the fifth, who is employed partly in a supervisory capacity. All five mixers have been exposed since 1977 when the process started.

A control population was obtained from other production workers and from managerial staff.

\section{USERS}

ETU was originally supplied to rubber manufacturers as a powder and later as a dust suppressed powder. Since 1978 all ETU from this factory has been supplied in the encapsulated form. The original reason for the encapsulation of many rubber chemicals was to promote the efficacy of the mixing process, ${ }^{10}$ but in the case of ETU and other compounds the main consideration is the health hazard. The NIOSH Health Hazard Evaluation ${ }^{8}$ found that when encapsulated ETU was substituted for the powdered form in manufacturing operations, occupational exposure is much less likely to occur, and its major recommendation was for encapsulation.

The main avenue of absorption is thought to be inhalation but since ETU is fat soluble, it could also be absorbed through intact skin. This is likely to be a less important route than inhalation, however, since protective clothing and gloves are worn.

\section{Methods}

All the exposed workers at both factories agreed to take part in the survey. They were all male with an age range of 26 to 62 at factory 1 and 28 to 56 at factory 2 .

Control populations were obtained from volunteer male workers on processes not involving ETU or related to compounds at factory 1 , and from other male shop floor workers and management at factory 2. As some contamination of factory 2 with ETU powder was suspected originally, male controls from two metal working factories in the same area were also obtained. Controls were matched for age and ethnic origin.

In each subject a clinical history was taken and a medical examination performed. Blood was collected by venepuncture and taken to the laboratory the same day.

\section{CHOICE OF THYROID FUNCTION TESTS}

Initially, total thyroxine $\left(T_{4}\right)$ was tested in all production workers, and thyroid stimulating hormone (TSH) was measured only if $T_{4}$ was abnormal. All the results fell within laboratory limits, however, and it was decided to measure $\mathrm{T}_{4}, \mathrm{TSH}$, and thyroid binding globulin (TBG) in all process workers, mixers, and controls, because this gives a more sensitive indication of thyroid dysfunction in the normal and low range than any of the tests alone. TSH is raised in $99 \%$ of cases of hypothyroidism owing to thyroid disease or from thyroid supressing drugs. ${ }^{.1}$ It was 
also necessary to measure TBG because if it is abnormal the significance of $\mathrm{T}_{4}$ changes is altered.

In factory 2 (mixers) tests were repeated at approximately six monthly intervals in order to confirm the initial low results and in order to evaluate whether such testing was useful in monitoring the workers' health. This also enabled each man to act as his own control so that changes in individual results could be related to changes in exposure levels. In the event such changes were slight, but all the results have been included.

\section{Results}

No worker or control had a history of thyroid illness or of taking thyroid medication and no clinical features of thyroid disease were found. One control was under treatment for pulmonary tuberculosis.

The data from the study are shown in the figure in which each individual is represented by a solid dot $(\bullet)$ placed at his measured $T_{4}$ level. Where several measurements were taken on the same individual, the solid dot marks the mean, and the individual measurements are shown as open dots (o) attached to their means by a line. The individual measurements from the three control series are shown separately on the figure, though they have been combined for the statistical analysis. The means of the control group (overall) and the two exposed groups are shown as small open squares (a). The bars attached to these represent \pm two standard errors for the estimated true population means. In other words, they show approximate $95 \%$ confidence intervals for the true means of the three groups.

Table 1 shows the means of each group and the mean and between individuals variance for the three groups on a log scale.

The difference in the variances presents a problem for the formal statistical testing of the differences between the groups by a straightforward $t$ test. Table II of the Biometrika tables ${ }^{12}$ gives critical values for the statistic

$$
\mathbf{v}=\sqrt{\text { difference of estimates of means }}
$$

for the comparison of two normal populations with separately estimated variances. These critical values depend on the sizes of the compared samples (degrees of freedom) and the ratio of the variance estimates. Table 2 shows these parameters and the resulting $p$ values (two-tailed). These data confirm the impression that the results from the mixers are clearly lower than those from the control group. The difference between the controls and the process workers is slight, and is due entirely to one individual with particularly low levels. The difference between the mixers and the process workers lies on the borderline of statistical significance.

The TSH results in the exposed process workers, mixers, and controls were not treated statistically because the increase that occurs in hypothyroidism is so large that mean levels would be uninformative. The TSH levels were within normal limits in all the controls and process workers (range $2 \cdot 1-5 \cdot 4 \mathrm{nmol} /$ 1). In one mixer the levels on two occasions were unacceptably high $(21.8 \mathrm{nmol} / 1$ and $17.0 \mathrm{nmol} / \mathrm{l})$ and he was investigated further and found to have premyxoedema.

The TBG levels and the $T_{4} /$ TBG ratios did not differ among the groups and were within normal limits.

\section{Discussion}

There is no evidence that thyroid function is severely affected by exposure to ETU at the levels experienced by these workers, nor was there any clinical evidence of any effect. Only one worker was considered to be hypothyroid on biological testing. The $T_{4}$ results in the exposed workers were generally, however, lower than those in the control subjects. Most of this difference in distribution was accounted for by the results from the mixers, results from the process workers being fairly evenly spread

Table 1 Comparison of $T_{4}$ results of groups

\begin{tabular}{llccl}
\hline Group & No of observations & Geometric mean (nmols/l) & Mean (on log $_{10}$ scale) & Variance \\
\hline Mixers & 22 & $80 \cdot 5$ & 1.906 & 0.0117 \\
Process workers & 23 & 96.4 & 1.984 & 0.0200 \\
Controls & 40 & $105 \cdot 7$ & 2.024 & 0.0054 \\
\hline
\end{tabular}

Table 2 Test statistic and $p$ values for difference between group means

\begin{tabular}{lllll}
\hline Contrast & $v$ & Degrees of freedom & Variance estimates ratio & $p$ \\
\hline Controls: process workers & 1.26 & 40,23 & 0.16 & $>0.10$ \\
Controls: mixers & 4.57 & 40,22 & 0.61 & $<0.01$ \\
Process workers: mixers & 2.08 & 23,22 & 0.25 & $\approx 0.05$ \\
\hline
\end{tabular}




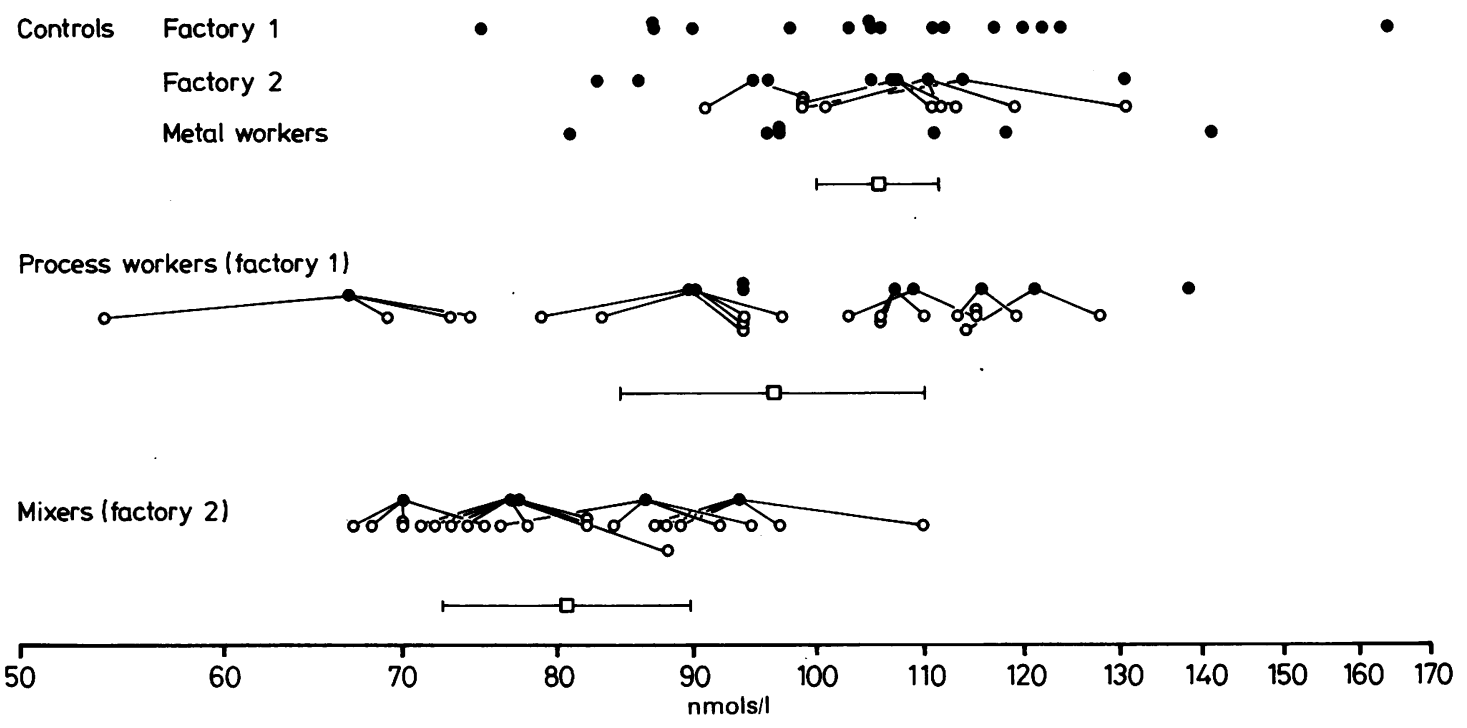

$T_{4}$ Levels in workers and controls.

over the range.

The mean $T_{4}$ results for all five mixers were below the laboratory mean of $100 \mathrm{nmol} / \mathrm{l}$; indeed only one result of the 22 in this group was above 100 . The levels in the process workers were more evenly spread, with five individuals below and five above - $100 \mathrm{nmol} / \mathrm{l}$. In the control group 13 individuals had levels below 100 and 21 above (see fig).

ETU resembles thiouracil in its effects, which are likely to be on the iodination of tyrosine after iodide has been oxidised to iodine. The resulting low levels of thyroxine would lead to stimulation of TSH production, and thyroid hypertrophy. The results seen in one mixer, low levels of thyroxine and high levels of TSH, are those that might be expected to result from a goitrogen. The generally low level of thyroxine would appear to bear out the contention that ETU was being absorbed by some workers.

There is at present no threshold limit value or control limit for ETU. The NIOSH Hazard Review ${ }^{8}$ suggested precautions in manufacturing and use, many of which are already being carried out in the United Kingdom. These include the exclusion of women of childbearing potential from exposure, prohibition of eating and smoking in the workplace, general hygiene, the encapsulation of the powder into masterbatch rubber, and local exhaust ventilation.

Personal respiratory protection should be worn when exposure to a dust or vapour hazard is likely, and NIOSH gives a level of $30 \mathrm{ppm}$ for this. NIOSH estimated that in the United States about 17000 employees in 24 different occupations were potentially exposed to ETU in their working environment, but some of the categories quotes must have minimal exposure-for example, only five of the 54 workers tested in their survey had significant exposure, and of these, only one handled ETU powder. If the material is encapsulated most of the other categories would disappear.

The mixing operation in the United Kingdom leads to greater exposure than the process work; this was predicted when it was started and unfortunately proved in practice to be the case, despite precautions. Attention should be paid to reducing exposure by improving housekeeping, by the use of local exhaust ventilation, and, when necessary, by personal respiratory protection.

I thank Mr J T Hodgson who provided the statistical analysis and the graph and Dr R D Jones who also gave statistical advice. The laboratories at Dudley Road Hospital and the Queen Elizabeth Hospital, Birmingham, performed the thyroid function tests and I am grateful for their help. Professor R Hoffenberg also gave helpful advice on the study. I also thank the management and workforce at Robinson Bros Ltd and Hermetic Rubber Co Ltd, for their cooperation, in particular Mr A Stevenson for technical advice. 


\section{References}

' Innes JRM, Ulland BM, Valerio MG, et al. Bioassay of pesticides and industrial chemicals for tumorigenicity in mice: a preliminary note. J Natl Cancer Inst 1969;42:1101-4.

${ }^{2}$ Ulland BM, Weisburger JH, Weisburger EK, Rice JM, Cypher $R$. Thyroid cancer in rats from ethylene thiourea intake. J Natl Cancer Inst 1972;49:583-4.

${ }^{3}$ International Agency for Research in Cancer. Working groups on the evaluation of the carcinogenic risk of chemicals in man. (IARC monographs on the evaluation of carcinogenic risk of chemicals to man.) Lyon: IARC, 1974:45-52.

${ }^{4}$ Gordon CF, de Fonso LR, Smith JR. A study of the thyroid function $(T, T, T S H)$ of workers involved in the manufacture and packaging of Dithane fungicide products. Rohm \& Haas Co RPAR, Dec 1977, Col II section 6 pp 17.

${ }^{5}$ Braverman LE, Lipworth L, Charkes D. A health survey of workers involved in the manufacture and packaging of Dithane fungicide with special reference to thyroid function. Rohm \& Haas Co RPAR, Aug 1978. Supplement to the Dec 1977 submission. Vol V, Section 29 pp 40.
- Lybarger JA. Report on the hazards of ETU to employees. Cincinnati: US Department of Health and Welfare Center for Disease Control. National Institute for Occupational Safety and Health, 1978.

${ }^{7}$ National Institute for Occupational Safety and Health. Ethylene thiourea. Rockville: NIOSH, 1978. (DHEW (NIOSH) publication 78-114: Current intelligence bulletin No 22.)

${ }^{8}$ National Institute for Occupational Safety and Health. Special occupational hazard review with control recommendations for ethylene thiourea. Rockville: US Department of Health, Education and Welfare, Public Health Service, Center for Disease Control, National Institute for Occupational Safety and Health, 1978. (DHEW (NIOSH) Publication No 79-109.)

' British Rubber Manufacturers' Association Ltd. Toxicity and safe handling of rubber chemicals. Code of practice. Birmingham: BRMA Ltd, Health Research Unit, 1978.

${ }^{10}$ Gregory AR. Encapsulation of hazardous materials. $J$ Environ Pathol Toxicol 1979;2:541-2.

"Siddiqui SA. Laboratory assessment of thyroid disorders. Hospital Update 1978 Feb.

12 Pearson ES, Hartley HO, eds. Biometrika tables for statisticians. Vol 1. London: Biometrika Trust, 1976. 